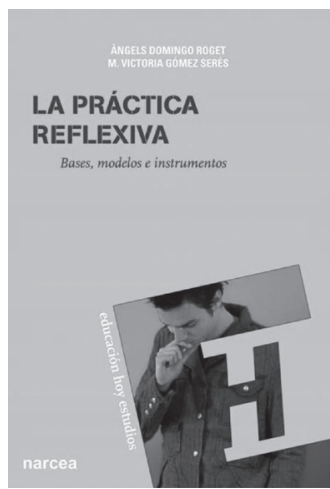

\title{
Reseña del libro \\ La práctica reflexiva. \\ Bases, modelos e instrumentos, de Àngels Domingo y M. Victoria Gómez
}

\section{Book review Reflective practice. Foundations, models and instruments, by Àngels Domingo \& M. Victoria Gómez \\ Compte-rendu du livre La pratique réflexive. Les bases, modèles et outils, d'Àngels Domingo y M. Victoria Gómez \\ Resenha do livro A prática reflexiva. Bases, modelos e instrumentos, de Angels Domingo e M. Victoria Gómez}

Fecha de recepción: 11 DE ABRIL DE 2013 / Fecha de aceptación: 19 DE NOVIEMBRE DE 2013

Encuentre este artículo en http://magisinvestigacioneducacion.javeriana.edu.co/

doi:10.11144/Javeriana.M6-13.RLPR

Escrita por MAURICIO PÉREZ-ABRIL PONTIFICIA UNIVERSIDAD JAVERIANA Bogotá, Colombia mauricioperezabril@gmail.com

Este libro, orientado a la práctica, se dirige a aquellos docentes, formadores, pedagogos, profesionales de la educación y responsables de instituciones educativas interesados en potenciar el desarrollo profesional mediante metodologías basadas en la reflexión.

Esta novedad editorial ofrece a sus lectores una base conceptual rigurosa sobre qué son la práctica reflexiva y el aprendizaje reflexivo y analiza el potencial didáctico que encierra la propia experiencia para el desarrollo personal e institucional.

¿Cuál es la finalidad principal del libro? Enseñar a educadores y formadores a convertir la reflexión ocasional en reflexión metodológica, de modo que revierta en la mejora práctica. Se trata, sin duda, de una propuesta formativa innovadora que logra una articulación profunda del conocimiento teórico y el conocimiento práctico, para lo cual presenta en sus páginas una cuidadosa selección de ambos campos de la práctica reflexiva y, sin agotar la temática, se propone contribuir al desarrollo de docentes reflexivos interesados en aprender de su propia práctica.

Las autoras, que acumulan una extensa experiencia docente, ponen a disposición del profesorado sus investigaciones sobre la reflexividad, así como la experimentación de la práctica reflexiva que han llevado a cabo en diversos contextos de formación docente

Para citar este artículo / To cite this article / Pour citer cet article / Para citar este artigo

Pérez-Abril, M. (2014). Reseña del libro La práctica reflexiva. Bases, modelos e instrumentos, de Àngels Domingo y M. Victoria Gómez. magis, Revista Internacional de Investigación en Educación, 6 (13), 195-196. 
Descripción del artículo | Article description | Description de l'article | Artigo descrição

Reseña del libro La práctica reflexiva. Bases, modelos e instrumentos, de Àngels Domingo y M. Victoria Gómez.

Domingo, À., \& Gómez, V. (2014). La práctica reflexiva. Bases, modelos e instrumentos. Madrid: Narcea. 152 pp. ISBN: 978-84-2771999-6 en Europa y América. Su dedicación a numerosos proyectos innovadores de capacitación, formación y desarrollo docente y formación de formadores les ha impulsado a desarrollar distintas metodologías y modelos basadas en la reflexión.

El primer capítulo del libro expone la necesidad de promover el desarrollo profesional del docente, así como las competencias que requiere esta profesión en el siglo XXI. Así mismo, los capítulos II, III, IV y V ofrecen al lector las bases conceptuales de la práctica reflexiva, con el objetivo de facilitar un conocimiento científico de la noción y de su consistencia como metodología formativa.

En el capítulo VI, tras aproximar al lector a las propuestas de carácter reflexivo del siglo XX, las autoras presentan sus propios modelos (20082013) plenamente formalizados y a la vez experimentados en foros avanzados de desarrollo docente en los que han mostrado su efectividad en la mejora de la práctica.

Por último, destinan la tercera parte del libro a presentar una valiosa selección de herramientas para el desarrollo de la reflexividad docente en contextos formativos o de aprendizaje profesional. Se trata de un instrumental inédito y experimentado que, por medio de investigaciones evaluativas, ha mostrado su efectividad. Los instrumentos más sencillos sirven para despertar la reflexividad docente y otros más elaborados para desarrollar la competencia reflexiva del docente.

Cada capítulo —excepto el $\mathrm{VI}$, que es eminentemente prácticoconcluye con una propuesta de desarrollo reflexivo que invita al lector a transferir a su práctica docente algunos de sus contenidos.

Con sus sugerentes propuestas formativas, modelos e instrumentos prácticos, el libro enseña cómo emprender y guiar la práctica reflexiva individual, grupal e institucional. Las formulaciones que se presentan han sido implementadas con éxito y pueden extrapolarse a diferentes países con docentes de las distintas etapas y niveles educativos. Además, se han aplicado por otros colectivos, pues la práctica reflexiva metodológica es válida para otros profesionales. Las formalizaciones de la práctica reflexiva que se han seleccionado para esta obra permiten su adaptación al contexto y al estilo docente de cada profesional.

Las autoras son creadoras e impulsoras de la Plataforma Internacional Práctica Reflexiva, que reúne a expertos en metodologías formativas basadas en la reflexión de 52 países.

La practica reflexiva. Bases, modelos e instrumentos constituye un referente obligado para la innovación en desarrollo docente y para impulsar la formación práctica en la Universidad, mediante la orientación reflexiva del currículo y de los practicum o las prácticas profesionales.

\section{Sobre el autor}

Mauricio Pérez-Abril es licenciado en Filología, con estudios de posgrado en Desarrollo Curricular y doctorando en Educación, de la Universidad Pedagógica Nacional de Colombia. Es docente e investigador de la Facultad de Educación de la Pontificia Universidad Javeriana, director del grupo de investigación Pedagogías de la Lectura y la Escritura y editor de magis, Revista Internacional de Investigación en Educación. 